\title{
THE SECOND U.K. SCOUT SATELLITE
}

\begin{abstract}
THE British National Committee on Space Research, the U.K. Steering Group on Space Research and the U.S. Nationel Aeronautics and Space Administration have agreed on the scientific instrument pryload for the second U.K. Scout satellite to be launched by the U.S. National Aeronautics and Space Administration. The scientific instruments, as in the first British Scout satellite, will be designed and provided by British scientists.

The experiments are designed to measure radio emissions from the Galaxy at wave-lengths too long to penetrate the Earth's atmosphere; to measure the vertical distribution of ozone in the regions of the atmosphere in which it is being formed; and to measure the number and size of fine dust particles encountered by the satellite. In addition, the galactic radio equipment is designed to gain information on the electrical condition of the high atmosphere.

It is expected that the satellite will be launched in about two years time. The orbit will probably pass over the United Kingdom and the United States, and it should be possible to receive radio information both in these countries and at stations in the British Commonwealth.

As for the first British Scout satellite, this one will be launched by a four-stage rocket system using solid propellants. It is expected that the satellite orbit will range between 300 and $2,000 \mathrm{~km}$. from the Earth. The instrumentation is being so arranged that the satellite will supply information on Galactic noise, atmospheric ozone and micrometeorite flux.
\end{abstract}

\section{Galactic Noise}

A project to measure the galactic noise in the frequency-range $0 \cdot 75-3 \mathrm{Mc} / \mathrm{s}$., and the exploration of the upper ionosphere, is to be carried out by Dr. F. Graham Smith, Mullard Radio Astronomy Observatory, Cavendish Laboratory, University of Cambridge.

Dr. Smith will have three objectives in mind: $(a)$ to measure the intensity of the galactic background at as low a frequency as possible under known conditions of receiver sensitivity and under known conditions of ionospheric effects on propagation and aerial impedance; (b) to watch for temporal or spatial variations of galactic radiation; (c) to explore the electron density in the upper $F$ region.

\section{Atmospheric Ozone}

Measurement of atmospheric ozone is under the direction of Dr. R. Frith and Dr. K. H. Stewart (Air Ministry, Meteorological Office, London). This will be carried out by two methods: (a) a spectrum scanning method; (b) a method in which a broad band of the spectrum is observed.

Dr. Frith's experiment will have as its main objective the measurement of the vertical distribution of ozone in the Earth's atmosphere as often and in as many places as possible. These measurements should add to our knowledge of the processes forming and destroying ozone, of the air motions which distribute it and of the effects of ozone on the thermal equilibrium of the upper atmosphere. Measurements will be made of the intensity of the radiation received from the Sun at selected wave-lengths in the ozone absorption region in the ultra-violet at times when the satellite is entering or leaving the Earth's shadow and the solar rays have to pass through the Earth's atmosphere to reach the satellite.

\section{Micrometeorite Flux}

The measurement of the micrometeorite flux is is being organized by Dr. R. C. Jennison (Nuffield Radio Astronomy Laboratories, University of Manchester, Jodrell Bank, Cheshire).

Dr. Jennison's experiment has as its objective the detection and measurement of micrometeorites encountered by the satellite. He will use a technique in which the holes formed in a thin metallic film by the impact of micrometeorites will be detected by an optical method. Sunlight passing through the holes will fall on a photosensitive strip of solar cells and give a signal from each hole in turn from which the number and size of the holes, and hence of the micrometeorites, can be deduced. The sensitivity is such that the holes formed by the particles, $1 \mu$ in diameter or greater, may be detected.

\section{THE BRITISH AGRICULTURAL HISTORY SOCIETY}

\footnotetext{
THE annual conference of the British Agricultural History Society was held during April 5-7 at Seale Hayne Agricultural College. On the first evening members heard papers from Mr. Peter Holmes, the County agricultural officer, and Dr. W. G. Hoskins, of Oxford. Mr. Holmes described the farming regions of Devon and did his best to disabuse his audience of the idea that Devonshire was entirely composed of the good red soils associated with the 'Glorious Devon' of the travel posters. He emphasized the importance of the hill-farming economy and explained also that there were large areas of indifferent shale soil in the north and north-east which were difficult to farm and not immensely productive.
}

Dr. Hoskins has recently been engaged in a study of the types of farmhouse on Dartmoor and made an appeal for more field work in the area for, as he said, "The history of the moor is as yet largely unwritten". He outlined briefly what is known of the earlier settlement of the moor and discussed its recolonization at the end of the Middle Ages. There are, he explained, still to be found many sixteenth- and seventeenth-century 'long houses' or buildings of the type that had both human dwelling and cattle stalls under one roof with a common doorway and central dividing passage.

The following day Dr. Hoskins led an excursion over the moor and showed the conference examples of 